\title{
A cross-sectional study on levels of second-hand smoke in restaurants and bars in five cities in China
}

\author{
R L Liu, ${ }^{1}$ Y Yang, ${ }^{2} \mathrm{M} J$ Travers, ${ }^{3} \mathrm{G}$ T Fong, ${ }^{4,5} \mathrm{R} \mathrm{J}$ O'Connor, ${ }^{3}$ A Hyland, \\ $\mathrm{L} L \mathrm{Li}^{6}{ }^{6} \mathrm{Y}$ Nan, ${ }^{2} \mathrm{G}$ Z Feng, ${ }^{2} \mathrm{O} \mathrm{Li}^{4}{ }^{4} \mathrm{Y}$ Jiang $^{2}$
}

${ }^{1}$ Chinese National Center for Disease Control and Prevention now School of Public Health University of California, Berkeley, California, USA): ${ }^{2}$ Chinese National Center for Disease Control and Prevention, Beijing, China; ${ }^{3}$ Department of Health Behavior, Roswell Park Cancer Institute, Buffalo, New York, USA; ${ }^{4}$ Department of Psychology, University of Waterloo, Waterloo, Ontario, Canada; ${ }^{5}$ Ontario Institute for Cancer Research, Toronto, Ontario, Canada; ${ }^{6}$ VicHealth Centre for Tobacco Control, The Cancer Council Victoria, Melbourne, Victoria, Australia

Correspondence to: R L Liu, Environmental Health Science, School of Public Health, 50 University Hall, University of California, Berkeley, California 94720, USA; ruiling liu@ berkeley.edu

Received 5 February 2009 Accepted 11 May 2009 Published Online First

11 December 2009

\section{ABSTRACT}

Objectives: To assess indoor second-hand smoke (SHS) exposure in restaurants and bars via $\mathrm{PM}_{2.5}$ (fine particles $2.5 \mu \mathrm{m}$ in diameter and smaller) level measurements in five cities in China.

Methods: The study was conducted from July to September in 2007 in Beijing, Xi'an, Wuhan, Kunming and Guiyang. Portable aerosol monitors were used to measure $\mathrm{PM}_{2.5}$ concentrations in 404 restaurants and bars. The occupant density and the active smoker density were calculated for each venue sampled.

Results: Among the 404 surveyed venues, 23 had complete smoking bans, 9 had partial smoking bans and $313(77.5 \%)$ were observed to have allowed smoking during sampling. The geometric mean of indoor $\mathrm{PM}_{2.5}$ levels in venues with smoking observed was $208 \mu \mathrm{g} / \mathrm{m}^{3}$ and $99 \mu \mathrm{g} / \mathrm{m}^{3}$ in venues without observed smoking. When outdoor $\mathrm{PM}_{2.5}$ levels were adjusted, indoor $\mathrm{PM}_{2.5}$ levels in venues with smoking observed were consistently significantly higher than in venues without smoking observed ( $F=80.49, p<0.001$ ). Indoor $\mathrm{PM}_{2.5}$ levels were positively correlated with outdoor $\mathrm{PM}_{2.5}$ levels (partial rho $=0.37 p<0.001$ ) and active smoker density (partial rho $=0.34, p<0.001)$.

Conclusions: Consistent with findings in other countries, $\mathrm{PM}_{2.5}$ levels in smoking places are significantly higher than those in smoke-free places and are strongly related to the number and density of active smokers. These findings document the high levels of SHS in hospitality venues in China and point to the urgent need for comprehensive smoke-free laws in China to protect the public from SHS hazards, as called for in Article 8 of the Framework Convention on Tobacco Control, which was ratified by China in 2005 .

Second-hand smoke (SHS) is the combination of smoke emitted from a cigarette or other burning tobacco products and the smoke exhaled by the smoker. SHS is a complex mixture of gases and particles, with the particles of fine to ultrafine size ranging from $0.02 \mu \mathrm{m}$ to $2 \mu \mathrm{m} .{ }^{1}$ These particles can be easily inhaled deep into lungs causing various diseases to multiple systems and organs in humans. Although not specific to SHS, large quantities of respirable particles (RSP) are emitted from burning cigarettes. Xiu et al found that indoor RSP levels in offices with smoking occurring were three times higher than levels with no smoking. ${ }^{2}$ Alpert et al also found that $93 \%$ of the indoor RSP were attributable to tobacco smoke during active smoking. ${ }^{3}$ Measuring the concentration of indoor fine particles with mean aerodynamic diameter no more than $2.5 \mu \mathrm{m}\left(\mathrm{PM}_{2.5}\right)$, which are recognised as a significant threat to public health, offers another assessment of indoor air pollution. ${ }^{4-6}$

SHS exposure is a completely preventable health risk factor, and there is no known safe level of SHS exposure. 7 In May 2003, the member countries of the World Health Organization (WHO) adopted a historic tobacco control treaty, the Framework Convention on Tobacco Control (FCTC). Article 8 of FCTC calls for the expansion of smoke-free places at the national and other jurisdictional levels in signatory countries to protect people from SHS hazards. On 4 July 2007, the second session of Conference of the Parties to the WHO FCTC drew up Guidelines on Protection from Exposure to Tobacco Smoke to assist parties in meeting their obligations under Article 8 of the WHO FCTC and to identify key elements of legislation necessary to effectively protect people from exposure to SHS.

In China, there are 350 million smokers. The overall prevalence is $35.8 \%(66.0 \%$ of males and $3.1 \%$ of females), ${ }^{8}$ which means that the risk for non-smokers to be exposed to SHS is very high. Some national prevalence studies in China reported that $53.0 \%$ of non-smokers in China were regularly exposed to SHS in $1996,{ }^{\circ}$ and $51.9 \%$ in $2002 . .^{8}$ SHS exposure occurs in various places, and the National Prevalence Survey in 2002 showed $82 \%$ of those passive non-smokers reported their SHS exposure in homes, $67 \%$ in public places and $35 \%$ in workplaces. $^{8}$

Hospitality venues-restaurants, bars and nightclubs, for example-are both workplaces for hospitality workers and places where the public spend, potentially, a considerable amount of time. Due to the lack of smoking regulations in these kinds of venues in China, hospitality workers and patrons alike are exposed to high levels of SHS. A study conducted in Beijing in 2004 on SHS levels of 14 public places, including 5 restaurants, showed that airborne nicotine concentrations in the 5 restaurants ranged from 2.07 to $28.72 \mu \mathrm{g} / \mathrm{m}^{3}$, with a median of $4.91 \mu \mathrm{g} / \mathrm{m}^{3}$, more than 14 times the concentration in hospitals and over 7 times that in schools. ${ }^{10}$ A cross-sectional study of SHS in 92 restaurants and bars in Beijing China in 2006 showed that the average of the indoor $\mathrm{PM}_{2.5}$ levels in venues where smoking was allowed was $280 \mu \mathrm{g} /$ $\mathrm{m}^{3}, 200 \%$ higher than that in venues with smoking restrictions $\left(93 \mu \mathrm{g} / \mathrm{m}^{3}\right){ }^{11}$

In China, objective assessments of SHS exposure are quite limited, especially in hospitality venues. As a party to the WHO FCTC, China is obligated to take effective measures to protect its public from SHS exposure as stated in Article 8. In recognition of its FCTC obligations, and as host of 
the 2008 Olympic Games, China promised that the Games would be smoke-free. Mostly driven by these two factors, China initiated a series of tobacco control activities in public places including hospitality venues to reduce SHS exposure. This study aims to describe a convenient and practical method to assess indoor SHS exposure in China and to provide scientific evidence for the Chinese government to adopt effective measures to reduce or eliminate SHS hazards in hospitality venues.

\section{METHODS}

\section{Sampling}

The study was conducted from July to September in 2007 in five cities in China: Beijing, the capital of China, located in northern China; Xi'an, a city in the Central Western part of China; Wuhan, a city in the Central part of China; and Kunming and Guiyang, two cities in southwest China.

In each city, hospitality venues were sampled from two districts following three steps. First, all the hospitality venues were divided into five categories according to Standards of Industry Classification issued by the National Statistics Agency of China, which are Chinese restaurants, Chinese fast food restaurants, Western restaurants, Western fast food restaurants and bars. ${ }^{12}$ Second, venues were sampled from each of the five restaurant types in the ratio 10:1:1:1:3 according to the number of restaurants and bars listed as hospitality venues on Yellow Pages websites; 50 Chinese restaurants, 5 Chinese fast food restaurants, 5 Western restaurants, 5 Western fast food restaurants and 15 bars were selected in each city. Third, restaurant size and average expenses per patron per visit according to the owners' reports were taken into account to keep a balance to some extent in these two aspects for the sampled venues. Via this procedure, a total of 405 hospitality venues were selected and surveyed in the 5 cities.

\section{Instruments and measures}

Fine respirable particles $\left(\mathrm{PM}_{2.5}\right)$ were used as the proxy measure for SHS. Data collectors in each city were trained directly to use a standard measurement protocol, which was consistent to the method detailed in the web-based training course (http://www. tobaccofreeair.org) developed by the Roswell Park Cancer Institute, New York, USA, and used in previous studies. ${ }^{5}$ Portable battery-operated aerosol monitors (TSI SidePak AM510 Personal Aerosol Monitors; TSI Incorporated, Shoreview, Minnesota, USA) fitted with $2.5 \mu \mathrm{m}$ impactors were used to sample the outdoor and indoor $\mathrm{PM}_{2.5}$ levels in each venue. The airflow rate was set at 1.7 litre/min using a Drycal DC Lite (BIOS, Butler, New Jersey, USA) flowmeter to ensure proper operation of the size-selective impactor. The calibration factor setting of 0.32 , suitable for SHS, ${ }^{513}$ was used and the monitor was set to a 1-min data log interval, which averages the 60 previous 1-s measurements. The portable device was calibrated to zero prior to each use by attaching a high efficiency particulate air filter according to the manufacturer's instructions.

To avoid disturbing people's normal behaviour during sampling, the monitor was placed in a bag with a short length of Tygon tubing (Saint-Gobain, Paris, France) attached to the inlet and left protruding on the outside. Logging of $\mathrm{PM}_{2.5}$ levels began at least 5 min outside of a venue before entering to provide baseline measurements. Since the monitor was in a bag worn by a data collector, it sampled the air from the zone around the data collector's waist. After outdoor measurements, the monitor kept logging when collectors entered a venue as patrons: they bought some food or drink and stayed for at least $30 \mathrm{~min}$ for indoor air sampling, and they tried to find a table as close as possible to the central position of the venue. The bag was placed on the table rather than on the floor or a chair, so that the air being sampled was at the level of occupants' normal breathing zone. The number of patrons and the number of burning cigarettes were recorded at the time of entry into the venue, at the time of exiting and every 15 min during the visit itself. The volume of each venue was calculated by using a sonic device (Zircon Corporation, Campbell, California, USA) to measure each of the linear dimensions of the room. If the room was irregular in shape, making it impossible to measure the volume using the sonic device, then the dimensions and volume were estimated by the trained data collectors. If a venue had a partial smoking ban, then the measurements were taken in the non-smoking area. Times of entry and exit, counts and occupants' smoking behaviours (eg, number of lit cigarettes) were recorded.

\section{Data analysis}

Data from each venue visit was downloaded to a computer using the TSI Trackpro V 3.4.1 software (TSI, Shoreview, Minnesota, USA). For each venue, the data logged during the minute of entry and exit was removed so that the remaining data points were either all from the indoor of a venue or all from its outdoor. These were averaged respectively to provide a mean $\mathrm{PM}_{2.5}$ level inside or outside the venue. The $\mathrm{PM}_{2.5}$ data from a bar in Wuhan was excluded from analysis due to its unexplainable extremely high indoor $\mathrm{PM}_{2.5}$ level considering the smokers, patron numbers, outdoor $\mathrm{PM}_{2.5}$ levels and other possible $\mathrm{PM}_{2.5}$ sources; thus, data from 404 venues were finally used for analysis.

For the $\mathrm{PM}_{2.5}$ data was log normally distributed, all statistical analyses used log-transformed $\mathrm{PM}_{2.5}$ concentrations. Pearson $\chi^{2}$ tests and Fisher exact tests were used to test proportion differences; geometric means of $\mathrm{PM}_{2.5}$ levels were compared between different cities, different venue types, and outdoors versus indoors using analysis of variance (ANOVA) tests and Student $t$ tests. Univariate analysis of variance (UNIANOVA) tests were used to compare the indoor $\mathrm{PM}_{2.5}$ levels in different venues with or without smoking observed after controlling for outdoor $\mathrm{PM}_{2.5}$ levels.

The occupant density (OD: the number of occupants per $100 \mathrm{~m}^{3}$ ) and the active smoker density (ASD: the number of burning cigarettes per $100 \mathrm{~m}^{3}$ ) were calculated for each establishment sampled. Spearman rho as well as partial correlation analyses were performed to determine the correlations between the $\mathrm{OD}, \mathrm{ASD}$, outdoor $\mathrm{PM}_{2.5}$ levels and indoor $\mathrm{PM}_{2.5}$ levels. Additionally, linear regression models were used to examine the relationship between indoor $\mathrm{PM}_{2.5}$ levels with outdoor $\mathrm{PM}_{2.5}$ levels, ASD, OD, different cities and different types of venues.

\section{RESULTS}

Table 1 presents the general characteristics of the hospitality venues where samples were taken in the 5 cities. The numbers of the five types of hospitality venues in each city were basically consistent with the proportion of 10:1:1:1:3 (as described in the Methods section), and the Pearson $\chi^{2}$ test $\left(\chi^{2}(16)=1.98\right.$, $\mathrm{p}=1.00)$ indicated no statistical differences among the proportions of different types of restaurants and bars in different cities. Maximum occupancy at $42.6 \%$ of the venues was $\leqslant 100$ patrons, while $33.2 \%$ of venues had a capacity of 101 to 300 
Table 1 Characteristics of hospitality venues surveyed in five cities during July to September 2007

\begin{tabular}{|c|c|c|c|c|c|c|}
\hline & Beijing, n (\%) & Wuhan, n (\%) & Xi'an, $\mathbf{n}(\%)$ & Kunming, n (\%) & Guiyang, n (\%) & Total, n (\%) \\
\hline \multicolumn{7}{|l|}{ Venue type: } \\
\hline Chinese dinner & $52(61.2)$ & $50(63.3)$ & $52(64.2)$ & $50(63.3)$ & $49(61.3)$ & $253(62.6)$ \\
\hline Chinese fast food & $8(9.4)$ & $5(6.3)$ & $5(6.2)$ & $5(6.3)$ & $6(7.5)$ & $29(7.2)$ \\
\hline Western fast food & $5(5.9)$ & $5(6.3)$ & $5(6.2)$ & $4(5.1)$ & $6(7.5)$ & $25(6.2)$ \\
\hline Bar & $14(16.5)$ & $14(17.7)$ & $15(18.5)$ & $14(17.7)$ & $14(17.5)$ & $71(17.6)$ \\
\hline \multicolumn{7}{|l|}{ Holding capacity: } \\
\hline$\geqslant 301$ seats & $14(16.5)$ & $16(20.3)$ & $8(9.9)$ & $13(16.5)$ & $23(28.8)$ & $74(18.3)$ \\
\hline Missing & $8(9.4)$ & $0(0.0)$ & $7(8.6)$ & $9(11.4)$ & $0(0.0)$ & $24(5.9)$ \\
\hline \multicolumn{7}{|c|}{ Average expense per patron: } \\
\hline$\leqslant 20 \mathrm{RMB}$ & $16(18.8)$ & $17(21.5)$ & $31(38.3)$ & $37(46.8)$ & $34(42.5)$ & $135(33.4)$ \\
\hline 21-50 RMB & $43(50.6)$ & $47(59.5)$ & $30(37.0)$ & $27(34.2)$ & $30(37.5)$ & $177(43.8)$ \\
\hline$\geqslant 50 \mathrm{RMB}$ & $26(30.6)$ & $14(17.7)$ & $17(21.0)$ & $12(15.2)$ & $14(17.5)$ & $83(20.5)$ \\
\hline Partial & $2(2.4)$ & $4(5.1)$ & $1(1.2)$ & $2(2.5)$ & $0(0.0)$ & $9(2.2)$ \\
\hline No bans & $76(89.4)$ & 73 (92.4) & $72(88.9)$ & 73 (93.7) & 77 (96.3) & $372(92.1)$ \\
\hline Total & $85(21.0)$ & 79 (19.8) & $81(20.0)$ & 79 (19.5) & $80(19.8)$ & $404(100.0)$ \\
\hline
\end{tabular}

patrons. About $44 \%$ of the venues had an average expense per patron per visit of $21-50 \mathrm{RMB}$ and a third of venues had an average expense per patron of $20 \mathrm{RMB}$ or lower, which suggests that most of the venues surveyed were frequented by people with moderate incomes. Only 23 restaurants completely banned smoking, and 7 restaurants and 2 bars had non-smoking areas, 4 of which were not completely separated from the smoking areas. In 1 of the 23 venues with complete smoking bans and in 5 of the 9 venues with partial smoking bans, smoking occurred during sampling, and only in 1 venue was there an intervention to stop the smoking.

Although there were numerically more restaurants with smoking bans in Beijing and Xi'an than the other cities, a Fisher exact test showed that there were no statistically significant overall differences across the five cities in the proportions of venues with no smoking regulations $\left(\chi^{2}(8)=10.12, p=0.199\right)$.

Table 2 presents the data collected from the 404 hospitality venues, which includes active smoking behaviours observed during sampling and geometric means of outdoor and indoor $\mathrm{PM}_{2.5}$ levels. Smoking was observed in $77.5 \%$ (313) of the surveyed venues during sampling and the overall average active smoker density of these 313 venues was 1.0 burning cigarettes per $100 \mathrm{~m}^{3}$. Pairwise comparisons showed no statistically significant differences in average ASD among the five cities, while it was statistically higher in bars (1.9) than that in restaurants $(0.8)(\mathrm{t}(76.67)=3.84, \mathrm{p}<0.001$, data not shown). The outdoor and indoor $\mathrm{PM}_{2.5}$ levels were $79 \mu \mathrm{g} / \mathrm{m}^{3}$ and $99 \mu \mathrm{g} /$ $\mathrm{m}^{3}$, respectively, in the 91 places without smoking observed, and they were $77 \mu \mathrm{g} / \mathrm{m}^{3}$ and $208 \mu \mathrm{g} / \mathrm{m}^{3}$, respectively, in the 313 smoking venues. Follow-up UNIANOVA tests showed that in each city, when the outdoor $\mathrm{PM}_{2.5}$ levels were controlled for as a covariate, the indoor $\mathrm{PM}_{2.5}$ levels of venues with active smoking observed were consistently significantly higher than that of venues without smoking observed $(F=80.49, p<0.001)$.

Table 3 shows the $\mathrm{PM}_{2.5}$ levels in venues stratified by smoking bans and cities. A paired sample Student $t$ test indicated that there was a significant statistical difference between indoor and outdoor $\mathrm{PM}_{2.5}$ levels $(\mathrm{t}(403)=19.95$, $p<0.001)$. When stratified by whether smoking was observed or not, outdoor $\mathrm{PM}_{2.5}$ levels were all similar to or lower than corresponding indoor $\mathrm{PM}_{2.5}$ levels even in venues without smoking observed (table 2), but for venues with complete smoking bans, outdoor $\mathrm{PM}_{2.5}$ levels were all similar to or higher than corresponding indoor $\mathrm{PM}_{2.5}$ levels (table 3). This indicated that though there was no observed smoking during sampling in some venues allowing smoking, smoking might have happened before sampling or may have been missed by surveyors during observation, thus some $\mathrm{PM}_{2.5}$ may be produced and kept inside the venue, leading to higher indoor $\mathrm{PM}_{2.5}$ levels than outdoors.

Table 2 Observation of cigarette smoking and $\mathrm{PM}_{2.5}$ (fine particles $2.5 \mu \mathrm{m}$ in diameter and smaller) levels $\left(\mu \mathrm{g} / \mathrm{m}^{3}\right)$ in restaurants and bars in five cities in China, July to September 2007

\begin{tabular}{|c|c|c|c|c|c|c|c|c|c|c|c|c|c|c|c|c|}
\hline & \multicolumn{8}{|c|}{ Smoking not observed } & \multicolumn{8}{|c|}{ Smoking observed } \\
\hline & \multirow[b]{2}{*}{$\mathbf{n}$} & \multirow[b]{2}{*}{ ASD } & \multicolumn{3}{|c|}{ Outdoor $\mathrm{PM}_{2.5}$ level } & \multicolumn{3}{|c|}{ Indoor $\mathrm{PM}_{2.5}$ level } & \multirow[b]{2}{*}{$\mathbf{n}$} & \multirow[b]{2}{*}{ ASD } & \multicolumn{3}{|c|}{ Outdoor $\mathrm{PM}_{2.5}$ level } & \multicolumn{3}{|c|}{ Indoor $\mathrm{PM}_{2.5}$ level } \\
\hline & & & GM & Min & Max & GM & Min & Max & & & GM & Min & Max & GM & Min & Max \\
\hline Wuhan & 11 & 0 & 36 & 21 & 73 & 47 & 21 & 113 & 69 & 0.9 & 50 & 15 & 168 & 188 & 32 & 1424 \\
\hline Xi'an & 25 & 0 & 184 & 120 & 317 & 196 & 58 & 523 & 56 & 1.5 & 193 & 32 & 309 & 404 & 165 & 1459 \\
\hline Kunming & 16 & 0 & 29 & 19 & 44 & 40 & 16 & 206 & 63 & 1.1 & 33 & 12 & 105 & 110 & 14 & 1007 \\
\hline
\end{tabular}

ASD, active smoker density: number of smokers per $100 \mathrm{~m}^{3}$; $\mathrm{GM}$, geometric mean with unit of $\mu \mathrm{g} / \mathrm{m}^{3}$. 
Table 3 Geometric mean outdoor and indoor $\mathrm{PM}_{2.5}$ (fine particles $2.5 \mu \mathrm{m}$ in diameter and smaller) levels $\left(\mu \mathrm{g} / \mathrm{m}^{3}\right)$ in venues with different smoking policies

\begin{tabular}{|c|c|c|c|c|c|c|c|c|c|c|c|c|}
\hline & \multicolumn{3}{|c|}{ Complete bans } & \multicolumn{3}{|c|}{ Partial bans } & \multicolumn{3}{|c|}{ No bans } & \multicolumn{3}{|c|}{ Total } \\
\hline & \multirow[b]{2}{*}{$\mathbf{n}$} & \multicolumn{2}{|c|}{$\mathrm{PM}_{2.5}$ level } & \multirow[b]{2}{*}{$\mathbf{n}$} & \multicolumn{2}{|c|}{$\mathrm{PM}_{2.5}$ level } & \multirow[b]{2}{*}{$\mathbf{n}$} & \multicolumn{2}{|c|}{$\mathrm{PM}_{2.5}$ level } & \multirow[b]{2}{*}{$\mathbf{n}$} & \multicolumn{2}{|c|}{$\mathrm{PM}_{2.5}$ level } \\
\hline & & Outdoor & Indoor & & Outdoor & Indoor & & Outdoor & Indoor & & Outdoor & Indoor \\
\hline Beijing & 7 & 120 & 102 & 2 & 89 & 93 & 76 & 126 & 248 & 85 & 124 & 225 \\
\hline Wuhan & 2 & 64 & 54 & 4 & 46 & 55 & 73 & 47 & 169 & 79 & 48 & 155 \\
\hline Xi'an & 8 & 163 & 130 & 1 & 146 & 159 & 72 & 194 & 361 & 81 & 190 & 323 \\
\hline Kunming & 3 & 26 & 19 & 2 & 32 & 162 & 74 & 32 & 94 & 79 & 32 & 90 \\
\hline Guiyang & 3 & 110 & 106 & 0 & - & - & 77 & 74 & 163 & 80 & 75 & 160 \\
\hline Total & 23 & 103 & 85 & 9 & 56 & 89 & 372 & 77 & 187 & 404 & 78 & 176 \\
\hline
\end{tabular}

Table 4 shows the Spearman and partial correlation analysis of $\mathrm{PM}_{2.5}$ levels, $\mathrm{ASD}$ and $\mathrm{OD}$. Indoor $\mathrm{PM}_{2.5}$ levels were significantly positively correlated with the outdoor $\mathrm{PM}_{2.5}$ level (Spearman $\mathrm{rho}=0.58, \mathrm{p}<0.001)$, ASD (Spearman $\mathrm{rho}=0.52$, $\mathrm{p}<0.001)$ and OD (Spearman rho $=0.33, \mathrm{p}<0.001)$ for bivariate Spearman correlation analysis. Partial correlation analysis also showed significant positive correlation between indoor $\mathrm{PM}_{2.5}$ levels and outdoor $\mathrm{PM}_{2.5}$ levels (partial rho $=0.37 \mathrm{p}<0.001$ ), and between indoor $\mathrm{PM}_{2.5}$ levels and ASD (partial rho $=0.34$, $\mathrm{p}<0.001$ ). There existed no significant correlation between indoor $\mathrm{PM}_{2.5}$ levels and $\mathrm{OD}$ when the outdoor level and ASD were controlled.

Linear regression analysis (table 5) also indicate that when other factors were adjusted, the occupant density and city were not significantly statistically related to the indoor $\mathrm{PM}_{2.5}$ level, while the outdoor $\mathrm{PM}_{2.5}$ level, the active smoker density and the type of the venues were all significantly statistically related to the indoor $\mathrm{PM}_{2.5}$ level. When the active smoker density was removed from the second model, the $\mathrm{R}^{2}$ decreased $16 \%$ $(0.08 / 0.49=0.16)$, that is, without the predictor of the active smoker density, the model's potentiality to explain the variability of the indoor $\mathrm{PM}_{2.5}$ level decreased $16 \%$, and this confirms the significant correlation between smoking and indoor $\mathrm{PM}_{2.5}$ level.

\section{DISCUSSION}

The study showed indoor $\mathrm{PM}_{2.5}$ levels are highly related to active smoking density. Places with smoking observed had much higher indoor $\mathrm{PM}_{2.5}$ levels than where no smoking was observed, while in places completely banning smoking, indoor $\mathrm{PM}_{2.5}$ levels were similar with outdoor levels. Even for venues with really high outdoor $\mathrm{PM}_{2.5}$ levels such as those in Xi' an and Beijing, indoor $\mathrm{PM}_{2.5}$ levels in venues with active smoking observed were significantly higher than in venues without smoking observed, adjusting for the outdoor $\mathrm{PM}_{2.5}$ levels. These indicate that although tobacco smoke is not the sole source of indoor $\mathrm{PM}_{2.5}$ in these venues, it is a major source.

$\mathrm{PM}_{2.5}$ levels in smoking places are consistently higher than that in smoke-free places across different countries. Hyland et al assessed indoor $\mathrm{PM}_{2.5}$ levels in 1822 public places across 32 countries from September 2005 to November 2006, ${ }^{5}$ using a standard measurement protocol that was adopted by this study. Figures 1 and 2 compare the results of that study and the present study. $\mathrm{PM}_{2.5}$ levels were measured in 92 hospitality venues in Beijing, China in 2006, we can see from fig 1 that, indoor $\mathrm{PM}_{2.5}$ levels either in places with smoking observed or in those without smoking observed were lower than indoor levels assessed in the present study. For places without smoking observed, this might be caused by the correspondingly higher outdoor $\mathrm{PM}_{2.5}$ levels possibly due to different seasons when the two studies were conducted. Venues in Beijing in this study were sampled in July and August, 2007, while the other study was conducted from February to August, which included the spring season with relatively lower outdoor $\mathrm{PM}_{2.5}$ levels. For places with smoking observed, the increased indoor $\mathrm{PM}_{2.5}$ level may be attributed to the correspondingly increased outdoor $\mathrm{PM}_{2.5}$ levels and the higher active smoker density. Additionally, indoor $\mathrm{PM}_{2.5}$ levels in places with smoking observed in this study are higher than that in places with almost equal ASD in the USA, and it is also higher in places without smoking observed than that in the USA and Ireland, which has enacted national comprehensive smoke-free indoor air laws (fig 2). This probably resulted from the higher outdoor $\mathrm{PM}_{2.5}$ levels in the five cities in China.

The only effective way to protect people from SHS is creating $100 \%$ smoke-free environments by implementing smoke-free laws and legislations. As of 1 April 2008, 15 countries and 45 regions, including Hong Kong, have enacted national or local comprehensive smoke-free laws and regulations in restaurants and bars. ${ }^{14}{ }^{15}$ However, in mainland China, smoking regulations have been limited to places such as museums, libraries and waiting rooms, and only Guangzhou and Shenzhen in Guangdong Province prohibit smoking in restaurants with air conditioning. ${ }^{16}$ So, at the time of this study, hospitality venues in mainland China had smoking policies dependent on their owners. This study shows that only 23 of the 404 (5.7\%) surveyed venues have smoking bans, and the indoor $\mathrm{PM}_{2.5}$ levels are very high in restaurants and bars, indicating that in mainland China, hospitality workers as well as patrons of these venues were at high risk of SHS exposure.

Table 4 Correlation analysis of indoor $\mathrm{PM}_{2.5}$ (fine particles $2.5 \mu \mathrm{m}$ in diameter and smaller) level with outdoor $\mathrm{PM}_{2.5}$ level, ASD and OD

\begin{tabular}{|c|c|c|c|c|c|}
\hline & \multicolumn{2}{|c|}{ Spearman correlation } & \multicolumn{3}{|c|}{ Partial correlation analysis } \\
\hline & rho & p Value & rho & p Value & Control variables \\
\hline Outdoor $\mathrm{PM}_{2.5}$ level & 0.58 & $<0.001$ & 0.37 & $<0.001$ & ASD, OD \\
\hline ASD & 0.52 & $<0.001$ & 0.34 & $<0.001$ & Outdoor $\mathrm{PM}_{2.5}$ level, $\mathrm{OD}$ \\
\hline OD & 0.33 & $<0.001$ & -0.05 & 0.352 & Outdoor $\mathrm{PM}_{2.5}$ level, ASD \\
\hline
\end{tabular}

ASD, active smoker density: number of smokers per $100 \mathrm{~m}^{3}$; OD, occupant density: number of occupants per $100 \mathrm{~m}^{3}$. 
Table 5 Regression models on the log value of indoor $\mathrm{PM}_{2.5}$ (fine particles $2.5 \mu \mathrm{m}$ in diameter and smaller) level and its related influential factors

\begin{tabular}{|c|c|c|c|c|c|c|c|c|c|}
\hline & \multicolumn{3}{|l|}{ Model 1} & \multicolumn{3}{|l|}{ Model 2} & \multicolumn{3}{|l|}{ Model 3} \\
\hline & Coefficient & $\mathrm{t}$ & p Value & Coefficient & $\mathbf{t}$ & p Value & Coefficient & $\mathbf{t}$ & p Value \\
\hline log(outdoor $\mathrm{PM}_{2.5}$ level) & 0.52 & 4.43 & 0.000 & 0.54 & 15.06 & 0.000 & 0.57 & 14.84 & 0.000 \\
\hline ASD & 0.41 & 6.45 & 0.000 & 0.41 & 7.30 & 0.000 & - & - & - \\
\hline OD & -0.03 & -0.57 & 0.568 & - & - & - & - & - & - \\
\hline Restaurants or bars* & 0.29 & 6.67 & 0.000 & 0.29 & 6.68 & 0.000 & 0.30 & 7.91 & 0.000 \\
\hline Type_ASD $\uparrow$ & -0.20 & -3.05 & 0.002 & -2.0 & -3.13 & 0.002 & - & - & - \\
\hline Kunming & -0.25 & -0.67 & 0.502 & - & - & - & - & - & - \\
\hline Guiyang & 0.41 & 1.04 & 0.299 & - & - & - & - & - & - \\
\hline Wuhan_pmout: & 0.39 & 1.28 & 0.202 & - & - & - & - & - & - \\
\hline Xi'an_pmout & -0.11 & -0.20 & 0.845 & - & - & - & - & - & - \\
\hline Kunming_pmout & 0.20 & 0.63 & 0.531 & - & - & - & - & - & - \\
\hline Guiyang_pmout & -0.43 & -1.13 & 0.258 & - & - & - & - & - & - \\
\hline
\end{tabular}

All coefficients were standardised.

${ }^{*}$ Restaurants were coded as " 0 " (reference group) and bars were code as "1"; †interaction item of type of venues (restaurants or bars) with ASD; tinteraction items of city and outdoor $\mathrm{PM}_{2.5}$ (pmout) levels.

ASD, active smokers density: number of smokers per $100 \mathrm{~m}^{3} ; 0 \mathrm{D}$, occupant density: number of occupants per $100 \mathrm{~m}^{3}$.

According to a study on hospitality patronage's attitudes towards smoke-free regulations in public places, only $30.0 \%$ and $19.8 \%$ of the patrons support completely banning smoking in restaurants or bars, respectively, ${ }^{17}$ and according to China Tobacco Control Report 2007, 52.2\% of restaurant owners worry that smoking bans would reduce their revenues, ${ }^{18} \mathrm{a}$ common belief that has been demonstrated to be false in systematic reviews of the economic impact of smoke-free laws across many jurisdictions in North America, Australia and other Western countries. ${ }^{19}$ These public opinion data as well as the observed smoking during samplings in non-smoking areas of 5 of the 9 venues with partial smoking bans and in 1 of the 23 venues with complete smoking bans demonstrate that challenges exist in China to implement legislation to protect the public from SHS hazards, particularly in hospitality venues.

This study demonstrated high levels of outdoor particle air pollution in some big cities in China and also demonstrated that levels are substantially worse than outdoors in indoor environments with smoking. There is currently a great deal of discussion on reducing the very high air pollution levels in China, which lead to over 400000 premature deaths each year, and result in total associated health costs estimated at 157 to 520 billion Yuan in $2003 .{ }^{20}$ In fact, billions of dollars were spent

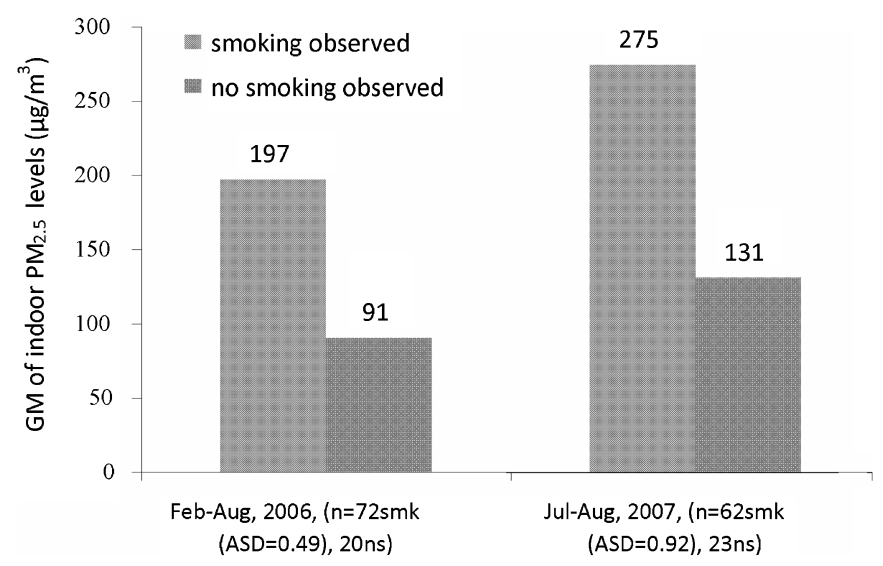

Figure 1 Geometric mean of $\mathrm{PM}_{2.5}$ levels of venues in Beijing by study (smk, smoking observed; ns, no smoking observed). to improve outdoor air quality for the recent 2008 Beijing Olympic Games. ${ }^{21}$ For exposed individuals, indoor smoking represents a harmful air pollution exposure at least as bad as outdoor pollution. However, comprehensive smoke-free indoor air policies are a simple, virtually cost-free solution that will dramatically reduce this exposure.

The current study measured $\mathrm{PM}_{2.5}$ exclusively, whereas other investigators have relied on nicotine measures for greater specificity to tobacco smoke exposure. $\mathrm{PM}_{2.5}$ is still an effective marker for SHS and also provides a more general air pollution measure that is effective for comparisons to other sources of pollution, such as outdoor particle levels. The laser photometer used in this study also provides continuous measurements demonstrating immediate changes in particle levels as conditions change or the device is moved between different microenvironments (fig 3).

Although this study adopted a convenience sample of venues, the results of this study were able to reflect the general situation of tobacco control and SHS exposures in hospitality venues in the five cities in China, as we have taken into account different types of venues, their possible proportions, their holding capacity and average expense.

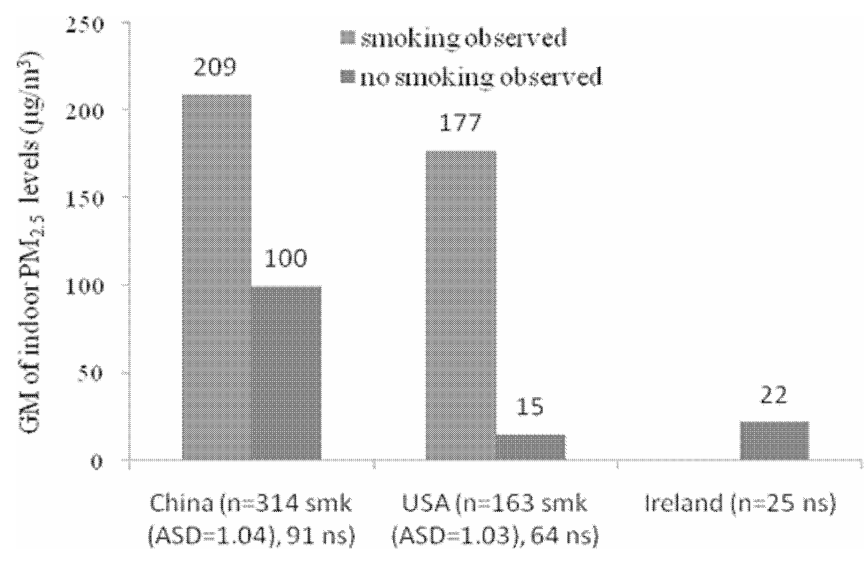

Figure 2 Geometric mean of indoor $\mathrm{PM}_{2.5}$ levels in China, USA and Ireland (smk, smoking observed; ns, no smoking observed). 


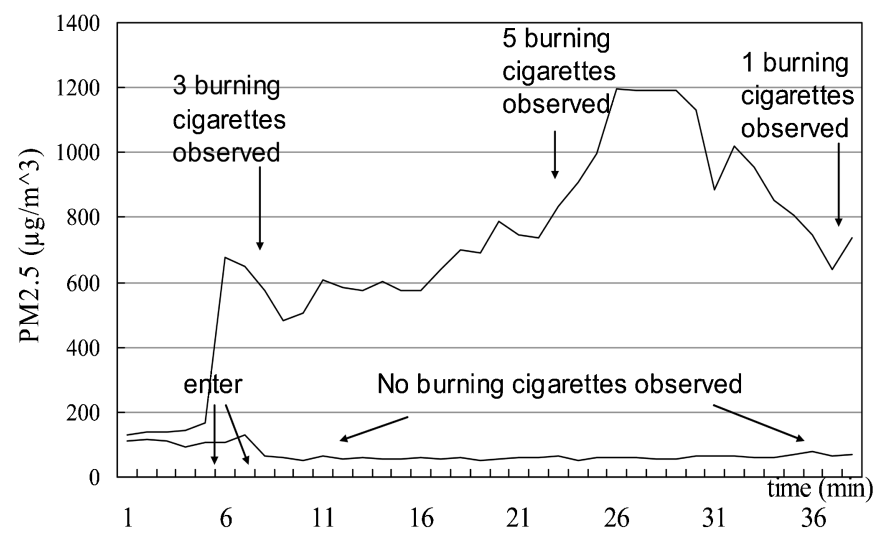

Figure 3 Real-time monitoring of $\mathrm{PM}_{2.5}$ levels in a restaurant with smoking observed and in another premises without smoking observed in Beijing.

\section{What this paper adds}

- The World Health Organization (WHO) Framework Convention on Tobacco Control (FCTC) calls for the expansion of smoke-free places in signatory countries to protect people from second-hand smoke (SH) hazards. However, up to the time when this study was conducted, smoking regulation was rare in hospitality venues in mainland China and quantitative assessments of SHS exposure in these venues were quite limited. This study is the largest study to assess indoor SHS exposure in hospitality venues in mainland China to date, and provides scientific evidence for the Chinese government to adopt effective measure to reduce or eliminate SHS hazards in hospitality venues.

- The results of this study show that, without smoking regulation, only a few $(7.9 \%)$ of restaurants and bars had smoking regulations, and SHS exposure in these places was very high. The $\mathrm{PM}_{25}$ levels in venues with observed smoking was more than two times the level in venues without smoking, and only when smoking was completely banned could the indoor $\mathrm{PM}_{25}$ levels become similar to corresponding outdoor levels. These results underline the importance of a comprehensive smoke-free policy in accordance with the FCTC.

- For the purpose of the 2008 Olympic Games, China initiated a series of tobacco control activities in public places, including hospitality venues, to reduce SHS exposure; this study could provide baseline information for further studies aimed at evaluating the effectiveness of the tobacco control activities in hospitality venues.

\section{Conclusions}

$\mathrm{PM}_{2.5}$ levels in places with smoking are significantly higher than those in smoke-free places and are statistically associated with active smoker densities. SHS exposures are very serious in hospitality venues in the five cities in China and comprehensive smoking regulations are commonly wanted to protect the public from SHS hazards.

Acknowledgements: The authors would like to acknowledge the Chinese National Center for Disease Control and Prevention (CDC) and the local CDC or health institutions representatives in each city for their role in data collection.

Funding: This project was supported by a special grant from the Chinese National Centers for Disease Control on Framework Convention on Tobacco Control annual implementation for 2007 and by a grant from the Roswell Park Trans-disciplinary Tobacco Use Research Center (P50 CA111236). MJT was supported by a grant from the Flight Attendant Medical Research Institute. The funding sources had no role in the study design, in collection, analysis and interpretation of data, in the writing of the report and in the decision to submit the paper for publication.

Competing interests: None.

\section{REFERENCES}

1. Klepeis NE, et al. Determining size-specific emission factors for environmental tobacco smoke particles. Aerosol Sci Tech 2003;37:780-90.

2. Xiu GL, Zhao YN, Zhang DN, et al. Analysis on respirable particle matters pollutants in offices. Shanghai Environ Sci 1999;18:202-4.

3. Alpert H, Carpenter C, Travers MJ, et al. Environmental and economic evaluation of the Massachusetts smoke-free workplace law. J Comm Health 2007;32:269-81.

4. Vardavas Cl, Kondilis B, Travers MJ, et al. Environmental tobacco smoke in hospitality venues in Greece. BMC Pub Health 2007;7:302.

5. Hyland A, Travers MJ, Dresler C, et al. A 32-country comparison of tobacco smoke derived particle levels in indoor public places. Tob Control 2008;17:159-65.

6. Semple S, Creely KS, Naji A, et al. Secondhand smoke levels in Scottish pubs: the effect of smoke-free legislation. Tob Control 2007;16:127-32.

7. US Department of Health and Human Services. The health consequences of involuntary exposure to tobacco smoke: a report of the Surgeon General. Atlanta, Georgia, USA: US Department of Health and Human Services, Centers for Disease Control and Prevention, National Center for Chronic Disease Prevention and Health Promotion, Office on Smoking and Health, 2006.

8. Yang GH, Ma JM, Liu N, et al. Survey of smoking and passive smoking in Chinese population 2002. Chinese J Epidemiol 2005;26:77-83.

9. Yang GH. Smoking in China: findings of the 1996 National Prevalence Survey. China Cancer 1998; 7:3-5

10. Huang L, Yang G, Guo X, et al. Investigation of contamination level of environmental tobacco smoke in public places and workplaces. J Environ Health 2007;24:477-9.

11. Kang JM, Jiang Y, Lin XG, et al. Study on the level of environmental tobacco smoke in restaurants and bars in Beijing, China. Chin J Epidemiol 2007;8:738-41.

12. National Statistics Agency of China. Standards of Industry Classification [S/OL] [2008-4-15]. http://www.stats.gov.cn/tibz/hyflbz/ (accessed 15 April 2008).

13. Klepeis NE, Ott WR, Switzer P. Real-time measurement of outdoor tobacco smoke particles. J Air Waste Man Assoc 2007:57:522-34.

14. American Non-Smokers' Rights Foundation. Overview list - how many smokefree laws [EB/OL]. (2008-4-1) [20084-15]. http://www.no-smoke.org/pdf/ mediaordlist.pdf (accessed 1 April 2008)

15. American non-smokers' rights foundation. Smokefree status of hospitality venues around the world [EB/OL]. (2008-4-1) [2008-4-15]. http://www.no-smoke. org/pdf/internationalbarsandrestaurants.pdf (accessed 1 April 2008).

16. Li YX, Jiang Y, Yang Y, et al. Analysis of laws and regulations on banning smoking in public places in China. J Environ Health 2007;4:221-3.

17. Ruiling L, Yan Y, Xiurong L, et al. Knowledge and attitudes towards second hand smoking among hospitality patronage in five cities in China. China J Epidemiol 2008;29:421-5.

18. Office of Leading Group for FCTC Implementation, Ministry of Health, People's Republic of China. China Tobacco Control Report 2007: create smoke-free environments, enjoy healthy life. Beijing, China: Office of Leading Group for FCTC Implementation, Ministry of Health, People's Republic of China, 2007.

19. Hyland A, Vena C, Cummings MK. A review of the economic effect of smoke-free restaurant and bar policies on the hospitality economy. Epidemiology 2000;11:687

20. The World Bank. The cost of pollution in China: economic estimates of physical damages. Washington, DC, USA: Rural Development, Natural Resources and Environment Management Unit, East Asia and Pacific Region, The World Bank, 2007

21. Stewart E. IOC praises efforts to reduce air pollution in Bejing. http://www.guardian co.uk/world/2008/aug/07/china.olympics2008 (accessed 12 November 2008). 